\title{
Peranan dan Impak Agama dalam Adaptasi Antarabudaya Pelajar Muslim Malaysia di United Kingdom
}

\author{
ABDUL LATIFF AHMAD \\ Universiti Kebangsaan Malaysia
}

\begin{abstract}
ABSTRAK
Kajian ini memberikan penekanan kepada peranan dan impak agama ke atas proses adaptasi pelajar Malaysia yang berada di luar negara. Agama adalah perkara asas dalam kehidupan pelajar Melayu beragama Islam daripada Malaysia. lanya turut menjadi asas kepada perhubungan yang dijalin dengan masyarakat di luar negara dan juga dalam kalangan masyarakat dari Malaysia yang turut sama berada di luar negara. Kajian ini turut melihat apakah impak dari mempraktikkan agama Islam di luar negara sama ada masyarakat luar mula memahami ataupun pelajar terkesan dengan pengalaman negatif di luar negara. Model Keluk U dari Lyssgard (1955) telah digunakan sebagai kerangka kajian ini. Seramai 10 orang pelajar prasiswazah telah ditemuramah di United Kingdom. Dapatan menunjukkan pelajar mengalami kejutan budaya namun ianya adalah satu fasa yang sangat singkat dan tidak memberikan implikasi yang berpanjangan. lanya juga adalah tidak sukar untuk mereka mempraktikkan agama masing-masing terutama dengan kemudahan yang ada sekarang dan juga kefahaman masyarakat tentang kepelbagaian agama dan budaya. Antara aspek yang ditekankan adalah sistem sokongan yang kuat dalam kalangan masyarakat negara asal ataupun masyarakat dalam kalangan golongan beragama Islam. Rata-rata pelajar Malaysia Muslim mempunyai pengalaman yang positif dan mereka merasakan bahawa masyarakat luar dapat menerima mereka seadanya. Walaupun penerimaan adalah baik, mereka pernah mendengar pengalaman-pengalaman negatif yang pernah dihadapi oleh rakan mereka.
\end{abstract}

Kata kunci: Agama, adaptasi, antarabudaya, Muslim, Malaysia.

\section{The Role and Impact of Religion on the Cultural Adaptation of Malaysian Muslim Students in Australia and United Kingdom}

\begin{abstract}
This research emphasises the role and impact of religion on the intercultural adaptation process of Malaysian students who are studying overseas. Religion has been the basis of life for Malay Muslim students from Malaysia. It is also the foundation for the relationships with the overseas communities and also with the Malaysian communities living abroad. This research looks at the impact of practising Islam overseas, whether the communities overseas are understanding or does students encounter a negative experience overseas. The U Curve model from Lysgaard (1955) has been chosen to frame the study. Ten undergraduate students have been interviewed in the United Kingdom. Findings showed that though students faced culture shock, it is a very short phase as there is no long-lasting impact. It was also not difficult for them to practice their religion especially facilities that are easily available today and also because of the understanding of the society on diversity in religion and culture. Among the aspects that were emphasized was a strong support system consisting of a member of society from the home country or those practising the Islamic religion. In general, the students had a positive experience where the local communities can accept them for who they are. Though acceptance has been good, they have heard of negative experiences faced by their friends.
\end{abstract}

Keywords: Religion, adaptation, intercultural, Muslim, Malaysia. 


\section{PENGENALAN}

Adaptasi antarabudaya adalah satu proses yang harus dilalui oleh seseorang pelajar yang ingin melanjutkan pengajian di luar negara. la boleh menjadi satu pengalaman yang mudah ataupun mungkin menjadi satu proses yang sangat mencabar. Perbezaan ini bergantung kepada beberapa perkara terutama sikap individu itu tersendiri sama ada beliau akan menerima peluang baharu itu sebagai sesuatu yang postif ataupun tidak. Tanggapan dan persepsi individu memainkan peranan yang penting dalam menghadapi situasi ini. Personaliti yang positif, berfikiran terbuka dan pengalaman individu ke luar negara sebelum ini akan memudahkan proses adaptasi ke dalam sesuatu budaya yang baharu. Namun, terdapat juga faktor-faktor luaran yang memberikan kesan kepada proses adaptasi tersebut. Antara faktorfaktor itu adalah kestabilan ekonomi, penerimaan dan keterbukaan masyarakat baharu, bahasa dan cuaca.

Costello (2015) mengatakan bahawa pengalaman belajar di luar negara bukan sahaja akan memberikan kesan kepada aspek pembelajaran dan juga akademik sahaja. Seseorang individu itu akan melalui satu proses pendedahan kepada senario berbeza yang akan memberikan pengalaman baharu membabitkan budaya dan bahasa. Mereka perlu keluar daripada zon selesa masing-masing dan berinteraksi dengan masyarakat luar.

Kim (2000) menceritakan bagaimana proses adaptasi itu sangat penting kerana ia mengubah persepsi penghijrah daripada pemerhati luar kepada sebahagian daripada suatu masyarakat baharu. Jikalau seorang individu itu kurang selesa dengan keadaan tempat baharu, ia akan memberi kesan kepada bagaimana untuk beradaptasi dengan suasana baharu itu. Maka mereka mungkin masih terbawa-bawa dengan budaya asal dan menyukarkan proses adaptasi.

Kajian ini melihat proses adaptasi pelajar-pelajar Muslim Malaysia yang sedang menyambung pengajian di United Kingdom. lanya akan memberikan penekanan kepada isuisu dan cabaran yang mereka hadapi sebagai pelajar di luar negara dan bagaimanakah ianya memberikan kesan kepada mereka.

\section{Adaptasi dan Kejutan Budaya}

\section{SOROTAN LITERATUR}

Macionis dan Gerber (2010) telah menakrifkan kejutan budaya sebagai "the personal disorientation a person may feel when experiencing an unfamiliar way of life due to immigration or a visit to a new country, a move between social environments, or simply when traveling to another type of life" (hlm. 54). lanya membincangkan tentang perasaan disorientasi yang dihadapi oleh seseorang apabila melalui satu proses migrasi atau lawatan ke negara baharu.

Chen (2009) telah menyenaraikan beberapa perkara yang boleh menyebabkan kejutan budaya. Antara perkara tersebut ialah cuaca, makanan, tempat tinggal dan peranan jantina. Perbezaan yang ketara antara dua negara terhadap perkara ini akan menyebabkan proses penyesuaian yang lebih sukar. Contohnya, jikalau seseorang dari negara Asia Tenggara ingin menyambung pengajian di United Kingdom, perubahan cuacanya agak ekstrem dan tempoh siang dan malam akan memberikan kesan. Jikalau seseorang itu hadir dari sebuah negara yang lebih dominan sikap maskulinnya, mungkin akan menghadapi kesukaran beradaptasi.

Ahrari, Krauss, Suandi, Abdullah, Sahimi, Olutokumbo dan Dahalan (2019) membincangkan tentang kewujudan stress dalam proses akulturasi. Pelajar antarabangsa memerlukan sistem sokongan sosial yang kukuh. Ramai yang menceritakan tentang perasaan 
homesick atau rindukan keluarga masing-masing. Terdapat juga pelajar yang meluahkan bahawa agak sukar untuk menjalinkan hubungan dengan pelajar tempatan kerana mereka kurang mesra. Namun ini mungkin disebabkan oleh dimensi nilai budaya yang berbeza. Terdapat pelajar antarabangsa yang menginteprasikan pelajar tempatan sebagai sombong dan tidak mesra namun terdapat kemungkinan bahawa pelajar tempatan itu sebenarnya pemalu dan kurang mengekspresikan diri masing-masing.

Ini turut dipersetujui oleh Baklashova dan Kazakov (2016) yang menceritakan halangan dari segi perbezaan budaya untuk memudahkan adaptasi antarabudaya. Mereka mengatakan kebanyakan yang ditemuramah mempunyai budaya yang berbeza dari Russia. Pelajar antarabangsa akan melalui kejutan budaya kerana perbezaan budaya ini. Terdapat sistem nilai, model komunikasi dan juga simbol yang sangat berbeza yang mungkin akan menyukarkan pemahaman pelajar antarabangsa baharu.

Mulyana dan Sri Eko (2017) telah menyenaraikan tanda-tanda yang dapat dilihat dalam seseorang yang mengalami kejutan budaya. Pertama, seseorang individu itu tidak mahu berinteraksi dengan masyarakat. Mereka mungkin merasa rendah diri dan segan untuk berkomunikasi dan berinteraksi dengan orang lain. Mereka lebih gemar berseorangan namun ini mungkin terbawa ke peringkat isolasi dan individu tersebut boleh mengalami masalah depresi. Kedua, seseorang indvidu tidak dapat memberikan fokus dan melihat kepada sesuatu tanpa makna dan perasaan. Ketiga, seseorang itu akan banyak mengelamun dan tidak dapat memberikan fokus kepada perkara yang memerlukan penumpuan. Keempat, mereka akan merasa lemah, di mana mereka akan menganggap diri mereka sebagai mangsa dan terperangkap dalam belenggu masalah. Kelima, seorang individu itu mungkin akan terbawabawa dengan emosi dan tidak mampu mengawal perasaan mereka. Seterusnya, mereka akan merasa sukar untuk berkomunikasi dengan orang luar. Mereka juga berpotensi untuk mengalami krisis identiti. Ini kerana mereka merasa sukar untuk menyesuaikan diri di tempat baharu dan tidak tahu siapakah mereka yang sebenarnya. Mereka akan mempersoalkan situasi di mana mereka berada dan mempersoalkan kenapa mereka berada di sana. Akhir sekali, mereka ingin pulang ke negara asal. Mereka tidak menunjukkan usaha lagi untuk mengadaptasikan diri di tempat baharu dan merasakan bahawa permasalahan yang dihadapi hanya akan selesai apabila mereka terus pulang ke negara asal.

\section{Adaptasi dan Agama}

Abdul Latiff, Salma, Ali dan Sabariah (2016) telah melakukan kajian tentang adaptasi pelajar Nigeria di Malaysia. Kedua-dua Nigeria dan Malaysia mempunyai ciri budaya yang berbeza namun dapat dilihat bahawa terdapat persamaan utama yang menjadi penghubung kepada pembangunan perhubungan antara kedua-dua komuniti iaitu agama Islam. Pelajar-pelajar Nigeria yang berada di Malaysia merasai perbezaan budaya yang wujud dalam kalangan kedua-dua masyarakat dan mereka turut mengatakan bahawa terdapat kesukaran untuk beradaptasi, namun agama Islam memudahkan penyatuan dengan masyarakat Malaysia dan hubungan terbina menerusi aktiviti di masjid dan surau.

Ini turut disokong oleh Nurul Syahidah dan Abdul Latiff (2018) yang menjalankan kajian tentang pelajar wanita Islam antarabangsa yang belajar di Malaysia. Kebanyakan daripada mereka mengetengahkan isu bahasa sebagai isu utama sewaktu beradaptasi di negara Malaysia. Namun proses yang memudahkan mereka adalah persamaan dari segi agama. 
Namun, kajian Balqis dan Abdul Latiff (2019) mendapati bahawa persamaan agama turut memainkan peranan dalam kejutan budaya yang dialami oleh pelajar. Kajian ini memberikan fokus kepada pelajar Malaysia yang berada di Indonesia unuk program pertukaran mobiliti selama satu semester. Pelajar mengandaikan bahawa kerana negara Indonesia mempunyai ramai penganut Islam maka segala aspek berkaitan adaptasi akan mudah namun terdapat beberapa situasi di mana perkara sebaliknya berlaku. Contohnya, terdapat perbezaan dari segi interaksi sesama jantina berbanding di negara asal. Pelajarpelajar yang telah ke Jepun dan Korea memaklumkan bahawa keadaan akan menjadi sukar contohnya untuk mencari ruang solat atau mencari makanan halal. Namun pengalaman di Jepun dan Korea ternyata lebih positif. Pihak yang dianggap sangat berbeza dari segi praktik budaya sebenarnya telah memberikan penumpuan yang lebih teliti untuk menjadikan keadaan lebih selesa bagi pelajar dari luar negara.

McDermott-Levy (2011) menceritakan tentang kesukaran untuk pelajar kejururawatan dari negara Arab yang menyambung pengajian di Amerika Syarikat. Agak sukar untuk mereka mempraktikkan agama mereka kerana kurangnya organisasi, struktur dan sistem sokongan yang dapat memudahkan mereka menjalankan ibadah. Ruang dan waktu solat menjadi isu kerana kekangan jadual dan kemudahan yang ada. Azan tidak kedengaran manakala ruang untuk beribadah sangat terhad. Ada pelajar yang menggunakan ruangan rak buku di perpustakaan untuk menunaikan ibadah solat. Kajian ini juga mendapati bahawa masyarakat tempatan tidak memahami tentang agama Islam kerana mereka dari jantina yang berlainan masih cuba untuk bersalaman. Mereka tidak tahu bahawa sentuhan fizikal antara jantina yang berbeza adalah tidak dibenarkan dalam Islam. Ini mungkin kerana kekurangan pendedahan tentang Islam di kawasan tersebut.

Abdul Latiff, Nur Zalila, Ali, Emma dan Hasrul (2014) telah melakukan kajian ke atas adaptasi pelajar Malaysia di United Kingdom dan Australia. Mereka mendapati bahawa kewujudan Persatuan Pelajar Malaysia banyak membantu pelajar untuk menjalankan aktiviti keagamaan di kampus. Selain daripada peluang bertemu pelajar Malaysia, ianya turut memberikan peluang untuk pelajar berinteraksi dengan pelajar Muslim dari negara lain. Namun, masih terdapat kekurangan dari segi ruang untuk bersolat, kebersihan suasana dan ruang ibadah.

Di dalam kajian yang sama, terdapat juga responden yang menceritakan bahawa agak lama beliau disiasat di lapangan terbang Sydney walaupun beliau mempunyai dokumen perjalanan dan visa yang sah. Pelajar yang bertudung turut mengalami pengalaman negatif sewaktu berada di luar negara. Pengalaman ini boleh memberikan tekanan kepada pelajar kerana ianya merupakan satu first impression ke atas penerimaan masyarakat luar terhadap mereka.

\section{Adaptasi dan Sistem Sokongan Pelajar}

Rabia (2017) menerangkan tentang proses adaptasi pelajar sarjana muda Arab di Universiti di Amerika Syarikat. Beliau telah menyenaraikan beberapa tema yang berkaitan dengan proses adaptasi pelajar Arab di sana. Di antaranya ialah kejutan budaya, masalah bahasa, perbezaan budaya dan isolasi. Dicadangkan agar universiti memainkan peranan untuk merapatkan pelajar Arab dengan warga tempatan. Program persediaan yang dikendalikan oleh universiti perlu diperkukuhkan untuk melancarkan proses adaptasi di antara pelajar Arab dan masyarakat tempatan. 
Wang, Li, Noltmeyer, Wang dan Shaw (2018) turut menggunakan model Lekuk U dalam memberi penerangan tentang adaptasi antarabudaya pelajar kolej antarabangsa di Amerika Syarikat. Wang et. al bersetuju dengan Rabia (2017) dan Presbitero (2016) yang memberikan kepentingan wujudnya program sokongan atau program intervensi yang berterusan dari pihak universiti untuk pelajar antarabangsa. Pelajar antarabangsa memerlukan sokongan dari pihak universiti untuk menjadi penghubung antara mereka dengan masyarakat tempatan. Walaupun banyak program telah dihasilkan oleh pihak universiti namun pembabitan pelajar tempatan masih berkurangan. Pelajar Amerika perlu lebih proaktif dan cuba untuk menjalinkan perhubungan dengan pelajar antarabangsa.

Perkara ini turut ditekankan lebih awal oleh Ding (2016) tentang kepentingan untuk berintegrasi dengan pelajar tempatan. Ding telah menjalankan kajian di Shanghai dan mendapati bahawa berlaku kesukaran untuk pelajar tempatan berinteraksi dengan pelajar antarabangsa. Di Shanghai, seolah-olah terdapat dua puak yang berbeza dan kurang berkomunikasi di antara satu sama lain. Ini membuatkan jurang perhubungan mereka sangat jauh dan integrasi merupakan sesuatu yang sukar untuk diadakan.

Rohaiza, Norhidayah, dan Nur Fatihah (2017) telah menjalankan kajian ke atas adaptasi pelajar Afrika di Malaysia. Antara dapatan utama yang dilihat adalah berkaitan tentang kepentingan hubungan yang terbina. Jikalau masyarakat tempatan dapat menerima kehadiran warga Afrika ini, ianya dapat memberikan satu sense of belonging warga Afrika terhadap komuniti di Malaysia. Ini merupakan motivasi untuk mereka terus mewujudkan satu suasana antarabudaya yang positif di Malaysia. Pengkaji telah menerangkan dua situasi bagaimana seorang warga Afrika akan dapat beradaptasi dengan jayanya. Pertama adalah menerusi penerimaan masyarakat tempatan dan kedua adalah berkaitan keutuhan kumpulan sokongan masyarakat asal dari Afrika yang telah berhijrah ke Malaysia. Sistem sokongan yang kukuh dalam kalangan warga Afrika menjadikan proses adaptasi lebih lancar.

\section{MODEL KELUK-U}

Kajian ini telah dijalankan menggunakan kerangka Model Keluk U yang dikemukakan oleh Lyssgard (1955). Model Keluk U ini mengatakan bahawa proses adaptasi yang dilalui oleh seorang pelajar di luar negara akan melalui empat fasa iaitu fasa bulan madu, fasa kejutan budaya, fasa pemulihan dan juga fasa adaptasi.

Fasa bulan madu adalah dalam tempoh permulaan kehadiran pelajar ke luar negara. Pada peringkat ini pelajar lebih teruja dengan tempat baru dan memandang tempat baru itu sebagai satu tempat yang positif dan menggembirakan. Fasa kedua adalah fasa krisis ataupun fasa kejutan budaya. Pelajar mula merindui keluarga dan rakan-rakan di negara asal atau mula merindui kehidupan di negara asal masing-masing. Pada peringkat ini, suasana kurang menggembirakan dan emosi pelajar akan sedikit terganggu.

Pada peringkat pemulihan, pelajar mula mencari solusi dengan keadaan diri dan cuba untuk memperbaiki keadaan dan cuba untuk menyesuaikan diri di tempat baharu. Di akhir sekali adalah di peringkat adaptasi di mana pelajar berjaya untuk mengadaptasikan diri di tempat baharu dengan jayanya. Mereka mula berintegrasi dengan masyarakat setempat dan menerima hakikat bahawa mereka perlu menyesuaikan diri dengan tempat baharu ini.

Pemilihan model ini sebagai kerangka adalah kerana terdapat hubungan dalam kalangan agama dengan proses adaptasi pelajar berdasarkan fasa yang disenaraikan. Agama yang dipegang oleh seorang individu membina persepsi individu dalam mengharungi 
kehidupan sebagai pelajar di luar negara dan perbezaan pemahaman dan praktis agama yang agak besar memberikan implikasi kepada pengalaman individu tersebut.

\section{METODOLOGI}

Seramai 10 orang pelajar Malaysia yang beragama Islam yang sedang melanjutkan pengajian di United Kingdom telah ditemuramah untuk kajian ini. Kajian ini bersifat eksploratori kerana ia merupakan kajian awal untuk mendapatkan maklum balas berkaitan isu-isu dan permasalahan yang wujud di United Kingdom. Pelajar yang dipilih terdiri daripada pelajar sarjana muda.

Jadual 1 menunjukkan senarai responden yang terdiri daripada pelajar yang ditemuramah yang sedang menyambung pengajian di peringkat ijazah sarjanamuda di beberapa universiti di United Kingdom.

\begin{tabular}{llll}
\multicolumn{3}{c}{ Jadual 1: Senarai Responden } \\
\hline Kod & Jantina & Lokasi & Program \\
\hline UK 1 & P & Canterbury, UK & Sarjana Muda \\
UK2 & P & Canterbury, UK & Sarjana Muda \\
UK3 & P & Canterbury, UK & Sarjana Muda \\
UK4 & L & Canterbury, UK & Sarjana Muda \\
UK5 & P & London, UK & Sarjana Muda \\
UK6 & L & London, UK & Sarjana Muda \\
UK7 & L & London, UK & Sarjana Muda \\
UK8 & L & London, UK & Sarjana Muda \\
UK9 & P & Canterbury, UK & Sarjana muda \\
UK10 & P & Essex, UK & Sarjana Muda \\
\hline
\end{tabular}

\section{DAPATAN KAJIAN}

Kajian ini akan membincangkan tiga tema utama yang berkaitan adaptasi antarabudaya pelajar Muslim dari Malaysia sepanjang pengajian di United Kingdom. Tema-tema ini memberikan implikasi ke atas para pelajar di beberapa fasa dalam Model Keluk-U.

\section{Adaptasi dan Kejutan Budaya}

Walaupun pelajar baharu pertama kali melanjutkan pengajian di luar negara, tetapi mereka tidak mendapat kejutan budaya yang terlalu ekstrem. Walaupun ada kerinduan kepada keluarga dan teman-teman di Malaysia, rata-rata pelajar merasakan kejutan budaya ini dianggap sebagai satu fasa yang tidak memberikan implikasi yang mengganggu sepanjang kehidupan di luar negara. Cara terbaik untuk mengubat rindu kepada keluarga adalah dengan menelefon mereka. Kini di zaman teknologi canggih, menelefon keluarga yang jauh tidak lagi membabitkan kos yang tinggi jika dibandingkan dengan zaman dahulu. Kini juga pelajar didedahkan dengan Internet video call yang menyenangkan lagi komunikasi dengan keluarga yang jauh.

How do I deal with my kesedihan, emm.. call family hari-hari ah.. selalu call ibu hari-hari.. call abah hari-hari..-UK 8

Terdapat juga pelajar yang dihantar oleh keluarga mereka di sana. Sistem sokongan dari keluarga telah membantu mereka untuk menyesuaikan diri di sana. Fasa bulan madu berlaku dengan baik sepanjang keluarga berada di sana. Pelajar mula merasakan sedikit 
tekanan dan terkesan dari sudut emosi apabila keluarga meninggalkan mereka untuk pulang ke tanahair.

\begin{abstract}
"Honestly tak susah sangat sebab abang saya pun dulu belajar dekat University of Kent masa saya foundation dia third year.. ahhh abang saya yang tolong semua.. mula-mula sedih jugalah kan tinggalkan Malaysia sebab first time saya keluar duduk jauh dari family tapi sebab abang saya ada, so Alhamdulilah ok" $-U K 1$

"My parents and my sister left for Heathrow, when they sent me together so like it was an emotional moment and that was probably the time where it hit me the hardest.. that I'm gonna be alone here and it's gonna be a challenging two years" - UK7
\end{abstract}

\title{
Adaptasi dan Agama
}

Terdapat beberapa isu dari sudut agama yang dialami oleh pelajar sewaktu mula sampai ke luar negara. Pelajar yang memilih untuk tinggal di kolej di kampus didedahkan dengan pengalaman yang baharu apabila kebanyakan kolej di sana adalah bercampur. Lelaki dan perempuan diletakkan di paras atau ruang sama dan ahli-ahli rumah tersebut terdiri dari pelbagai bangsa dari seluruh dunia. Dalam konteks ini, pelajar perlu belajar menghormati budaya orang lain dan di waktu yang sama belajar untuk beradaptasi dengan situasi yang baharu.

"Saya based on daripada experience saya tahun lepas eh, saya duduk di Darwin College, Darwin College satu rumah tu dia lima orang dan semuanya adalah campur-campur, international students ada, apa semua ada" - UK2

Kejutan budaya dari sudut mempraktikkan agama adalah lebih mencabar kepada kebanyakan pelajar-pelajar Malaysia di United Kingdom. Pencarian ruang untuk solat, perubahan waktu solat yang mendadak dan aktiviti berpuasa merupakan antara kesukaran yang dihadapi oleh para pelajar sewaktu di United Kingdom.

Musim sejuk mempunyai durasi waktu siang yang lebih pendek menjadikan pelajar agak terkejar-kejar untuk mencari ruang untuk mengerjakan solat. Berbanding dengan Malaysia, tiada perubahan yang mendadak kepada waktu solat kerana Malaysia mempunyai waktu siang dan malam yang seimbang. Dengan pertembungan waktu kuliah, pelajar perlu merancang setiap perjalanan harian mereka.

"Kat sini dia punya timing dia pun berubah-ubah tak macam Malaysia, so... ah yang struggle-nya time winter lah kot, sebab waktu solat dia pendek, so nak kena kalau ada kelas yang panjang tu ah then kena pandai-pandai ah cari masa untuk keluar solat sekejap ah then join class balik". - UK1

"Mostly waktu solat dia..especially after the daylights saving during winter.. macam terkejar-kejar sangat nak solat after class, during class, ah macam kadang-kadang tu rasa, eh baru solat Zohor, nak solat Asar dah.. macam tu.."UK3 
Keadaan kesedaran terhadap kepelbagaian agama dan budaya turut membuatkan banyak rumah dan ruang ibadah diwujudkan di United Kingdom. Di kota London sendiri kehadiran masjid yang sedia terbina melambangkan peningkatan orang Islam di negara tersebut. Salah seorang responden turut memaklumkan bahawa Datuk Bandar London adalah seorang Muslim maka dengan itu menganggap isu-isu berkaitan Islam akan diberikan keutamaan.

Pelajar turut didedahkan dengan kewujudan Multi-Faith Centre (Pusat Antara Agama) di United Kingdom. Pusat ini merupakan tempat untuk masyarakat dari pelbagai budaya dan agama menjalankan ibadah masing-masing. Setiap agama diberikan ruang untuk menjalankan ibadah berdasarkan agama mereka tersendiri. Seorang yang beragama Islam akan turut berkongsi ruang tersebut dengan penganut agama Kristian atau Buddha contohnya. Ini juga adalah untuk mengangkat kesedaran untuk hormat-menghormati dalam kalangan mereka yang menganut agama berbeza.

It's not that hard actually because there's plenty of mosques that you can go, like it's East London because, I mean London itself dorang dah elect a new mayor which is a Muslim, which I'm pretty sure like they would give more priority towards the Muslim community in London- UK7

Tapi kalau nak cepat solat dekat situ, tapi dia tak panggil as surau la. Nama dia multi faith centre. So maksudnya semua agama boleh masuk la. Tapi dia macam dah segregate la, means muslim dah ada tempat solat, tempat wudhu' pun ada. And kalau agama Kristian dia dah ada satu hall.. - UK10

Namun tidak semua tempat mempunyai ruang khas yang disediakan untuk ibadah solat. Suasana di sana berbeza. Pasaraya membeli-belah tidak mempunyai kemudahan surau seperti di Malaysia. Pelajar turut menceritakan idea kreatif mereka mencari ruang untuk bersolat. Ada yang menceritakan bagaimana menggunakan fitting room di pasaraya besar sebagai ruang untuk menunaikan ibadah solat.

So kalau travel if nak solat, just cari macam fitting room ke, then you can solat there - UK9

Selain daripada itu aktiviti puasa juga agak mencabar. Sewaktu rakaman temuramah ini dilakukan, bulan Ramadhan di United Kingdom jatuh pada musim panas menjadikan tempoh waktu berpuasa menjadi lebih lama. Tempoh waktu berpuasa juga boleh dikira agak ekstrem kerana waktu siang yang lebih panjang namun para pelajar mengambil pengalaman ini sebagai sesuatu yang harus diharungi oleh penganut agama Islam di luar negara. Walaupun tempoh ibadah dijalankan agak panjang, pelajar turut berfikiran positif dan mengatakan bahawa biarpun berada dalam keadaan musim panas, namun suasana di sana masih lagi sejuk (berbanding dengan Malaysia) dan memudahkan ibadah puasa mereka.

Subuh pukul dua, and then buka puasa pukul sembilan, hahaha (giggles) tapi Alhamdulilah okay, tak ada rasa haus pun sebab cuaca walaupun time tu tengah summer, tengah panas tapi dia masih early summer so dia still sejuk lah, bolehlah, okay-lah, puasa so far okay- UK 7 
Dari segi mendapatkan makanan halal pula, sememangnya pelajar-pelajar ini mengatakan bahawa mereka tidak mempunyai sebarang masalah. Bandar-bandar besar di United Kingdom kian kaya dengan kepelbagaian budaya. Migrasi kian meningkat dan corak budaya kian meriah di sini. Daging halal tidak lagi menjadi isu. Jikalau pada tahun 70-an, 80an dan awal 90-an sememangnya agak sukar untuk mendapatkan makanan halal di negara benua eropah ini namun kini kesedaran tentang keperluan makanan halal kian meningkat dan pelajar boleh membelinya dengan mudah. Bukan sahaja makanan basah halal yang senang didapati namun kini semakin banyak restoran yang menjual makanan halal di sana. Restoran halal ini terdiri daripada makanan halal dari pelbagai negara di dunia. Selain makanan Arab, makanan Malaysia juga semakin mudah untuk dibeli di restoran-restoran terutamanya di kota London.

Sekarang memang dah banyak dah some part in London memang dah banyak Muslim dah duduk. And then in my town, kat Canterbury pun ada kedai umm macam Arab or and then ada surau dekat university - UK 9

Makanan halal okay, mostly kita beli dekat supermarket ada section halal, mostly kita masak kat rumah lah, kalau nak makan kat luar tu quite costly, so kita prefer masak sendiri - UK3

Selain daripada makanan halal, sebenarnya pelajar turut menceritakan tentang kerinduan mereka terhadap makanan Malaysia. Mereka turut membawa banyak makanan dan stok masakan daripada Malaysia untuk mengubat kerinduan kepada masakan di Malaysia.

I've been quite, for me I think the biggest challenge is actually food because you know in Malaysia we pretty much take for granted most of it so we assume it's halal, but l've been quite lucky that in my dorms and in my hall there is, it's canteen style food so, there's always been halal or vegetarian option - UK5 First thing is food, like I have to bring a lot of from Malaysia. For example Maggi, kicap and everything. That's the most important thing lah because I'm Malaysian kan, and the second thing that I worry about is like when I'm here, I'm in London kan so I don't know whether there's halal food or just not many choices of halal food here, but when I got here, East London already developed like quite developed, there's many halal restaurants you can get here like Arab food or Malaysian food as well - UK6

Pelajar wanita turut mendedahkan tentang pemakaian hijab di luar negara. Ada yang merasa sedikit tertekan dengan pemakaian hijab dan persepsi masyarakat luar dan ada yang merasakan ianya tiada isu kerana penerimaan masyarakat luar yang lebih memahami tentang pemakaian hijab. Ramai yang mengatakan bahawa mereka perlu memainkan peranan sebagai duta agama Islam. Ramai masyarakat luar yang bertanyakan kenapa mereka memakai hijab. Persoalan oleh masyarakat luar ini dianggap sebagai satu peluang untuk mereka turut mendalami tentang pengetahuan agama mereka supaya apa yang mereka kongsikan adalah sahih. Ini memberikan peluang juga kepada mereka untuk lebih memahami agama dan memudahkan mereka untuk menjawab persoalan. 
United Kingdom juga adalah antara pusat migrasi yang popular dalam kalangan masyarakat Islam. Oleh itu visual pemakaian hijab oleh golongan wanita Islam adalah satu kebiasaan terutama dibandar-bandar besar. Cuma masih ada pelajar yang cuba untuk memakai hijab yang warnanya tidak terlalu terang dan tidak terlalu menarik perhatian orang. Walaupun pelajar tidak terdedah dengan sesuatu yang boleh mengancam ketenteraman mereka namun ada pelajar yang mendengar bahawa wujudnya diskriminasi di tempat lain atau terdapat isu yang berlaku ke atas kawan-kawan mereka.

\begin{abstract}
"Mungkin masa dekat kelas... saya seorang je Melayu dalam tu and even seorang je Muslim.. rasa macam kalau masuk kelas tu.. emmm masa mulamula datang lah, rasa macam tak nak pakai tudung yang terlalu outstanding, saya selalu pakai tudung hitam, coklat sama dengan rambut orang, so macam tak nak orang perasan saya pakai tudung, macam tulah.. so tapi lama-lama okay dah."- UK3

So semua macam pandang pelik, pakai apa tu? Ada sorang pernah dapat question macam 'What are you wearing', 'Why are you wearing this?' Macam pelik sangat. UK10

Diorang pernah cerita...not in UK la, but in other country, diorang tanya kenapa pakai hijab, nak buat apa datang country dia...and then my friend dia nak pergi this country... and the immigration tahan because she was wearing hijab.. and then they searched for her bag and so on....so macam extra security $-U K 9$
\end{abstract}

\title{
Adaptasi dan Sistem Sokongan Pelajar
}

Sewaktu berada di luar negara, ramai pelajar Malaysia mengatakan bahawa sistem sokongan daripada rakan-rakan di sana adalah sangat penting. Ramai yang menceritakan tentang pentingnya ada rakan-rakan dari Malaysia yang turut melalui proses ini dengan mereka. Selain rakan-rakan dari Malaysia, mereka turut menceritakan tentang kepentingan untuk mempunyai rakan-rakan Muslim dari negara lain. Sistem sokongan ini penting untuk merasakan bahawa mereka adalah sebahagian daripada sistem sosial di negara tersebut. Mereka mempunyai satu kebergantungan untuk berada di dalam kelompok yang sama. Ini memberikan satu zon yang selesa kepada mereka ketika banyak faktor luaran berubah dan menjadi cabaran baharu kepada mereka.

I was quite lucky there were about 5 or 6 other Malaysians in my batch and it's so happen I knew some of them so I felt like I had a bit of a support group but- UK5

Tapi sebenarnya kawan-kawan saya yang daripada Malaysia sendiri macam ramai yang ada kat sini, jadi diorang sendiri yang bantu saya untuk adapt kat sini. - UK2

Then few months later jumpa few more Malaysians and then rasa lagi terisi lah kehidupan ni- UK3 
Pelajar-pelajar turut mendedahkan bahawa mereka menghadapi kesukaran untuk berkomunikasi dengan masyarakat tempatan atau masyarakat antarabangsa di sana. Mereka bimbang mesej yang cuba disampaikan tidak difahami oleh pihak di sana dan mereka turut mengatakan bahawa sebelum ini mereka tidak pernah didedahkan dengan kepelbagaian kaum lalu pengalaman baharu ini memberikan kesedaran baru kepada mereka untuk menyesuaikan diri.

I have to, interact with people from Africa, people from Poland, from Scandinavia, and everything but like by time you would like get used to it. Just in terms of interactions with people there would be culture shock- UK6

So it's probably the most difficult part of it is trying to communicate with locals and how to interact with them so that the messages that you trying to convey gets to them and their understand that point - UK 7

Saya study dekat UiTM Penang, so kami from a you know Malaysian IPTA so kat situ semua Melayu semua, like bumiputra tu ah... so quite different ahh bila saya mai sini orang like from different countries, all over the world, agak pelikk ah gak- UK8

Kajian-kajian lepas banyak menunjukkan bahawa pelajar memohon untuk lebih banyak aktiviti dijalankan di universiti bagi mengeratkan lagi persahabatan dalam kalangan masyarakat tempatan dan pelajar antarabangsa. Universiti dicadangkan untuk menganjurkan program dalam kalangan pelajar bagi memudahkan integrasi namun dapatan kajian kali ini sedikit berbeza. Rata-rata pelajar banyak mencadangkan agar individu perlu memainkan peranan yang lebih aktif dalam proses penyesuaian diri ini. Mereka perlulah bersedia dari segi fizikal dan mental. Dari segi fizikal, perubahan cuaca yang mendadak akan membolehkan seseorang itu jatuh sakit manakala dari segi mental pula ia turut membabitkan isu emosi dan kesediaan untuk bersaing dan berdepan dengan masyarakat dari luar negara. Mereka mencadangkan bahawa pelajar perlu mencari kumpulan sokongan tersendiri.

I think you need to make more about on your own, you need to make the effort like make friends or join clubs but I think coming overseas in general, be open to making friends and don't just stick to Malaysians because, it's a good support based but if you just stay friends with Malaysian, then why did come abroad you know? - UK5

Pengalaman berkomunikasi dan menjalinkan hubungan dengan masyarakat tempatan adalah sangat penting kerana ia dapat menunjukkan bahawa seseorang individu itu telah mencapai proses adaptasi, proses akhir di dalam Model Keluk-U.

Saya rasa pengalaman paling berharga kat sini, I got to learn their culture, saya boleh tengok macam mana cara depa, interaction depa dengan orang luar, cara depa hidup, cara diorang bercommunicate, saya amik yang postif je ah dari situ- UK 8 


\section{PERBINCANGAN}

Berdasarkan data yang diterima menerusi sesi temuramah dengan pelajar-pelajar Malaysia di United Kingdom, proses adaptasi yang dilalui oleh pelajar adalah stabil. Beberapa orang pelajar telah memaklumkan bahawa mereka telah dihantar ke sana bersama ahli keluarga dan ini memudahkan proses adaptasi mereka di luar sana. Proses bulan madu dilalui tanpa sebarang masalah. Kejutan budaya itu wujud namun bukanlah dianggap sebagai satu proses yang menganggu kelancaran kehidupan di luar negara. Kebanyakan pelajar melalui proses kejutan budaya apabila keluarga mereka telah pulang ke Malaysia dan mereka terpaksa melalui kehidupan dengan sendiri namun kehadiran ahli keluarga berjaya membantu menguruskan penempatan mereka di sana. Kemungkinan pelajar yang pergi sendiri ke luar negara akan mengalami proses adaptasi yang berbeza.

Selaras dengan pandangan Chen (2009), kejutan budaya juga wujud berikutan perbezaan budaya yang agak ketara. Contohnya dari segi penginapan kolej yang mencampurkan pelajar dari pelbagai bangsa dan jantina. Ini mungkin sesuatu yang kekok terutamanya pelajar wanita yang memakai hijab kerana perlu menjaga aurat mereka.

Dari sudut agama, pelajar turut menyenaraikan bebarapa isu yang harus dilalui oleh mereka. Ruang solat yang bercampur dengan agama lain, waktu solat yang pendek dan pertembungan dengan perkuliahan, waktu berpuasa yang panjang adalah antara isu yang dibangkitkan. Walaupun ini merupakan satu cabaran kepada pelajar, kebanyakan pelajar Malaysia tidak menjadikannya sebagai isu yang memberikan kesan kepada adaptasi mereka ketika berada di luar negara. Ini berbeza dengan pandangan McDermott-Levy (2011) yang menceritakan pengalaman pelajar kejururawatan di Amerika Syarikat. Kemungkinan keadaan di United Kingdom adalah lebih baik dan teratur di mana ruang-ruang ibadat contohnya telah disediakan. Kepelbagaian budaya dan agama di luar negara diambil kira dalam penyediaan fasiliti. Dari sudut makanan pula, makanan halal sangat senang untuk didapati. Tiada kejutan ketara berkaitan makanan. Permintaan barangan halal juga meningkat menjadikan akses kepada barangan ini mudah. Migrasi telah menjadikan United Kingdom sebuah negara yang bersifat multibudaya.

Dari segi pemakaian hijab, masyarakat luar mula memahami dan menghormati kepelbagaian agama dan budaya. Berdasarkan pengalaman pelajar sendiri, mereka tidak menghadapi isu dengan pemakaian hijab namun pernah mendengar masalah atau isu yang dihadapi oleh pelajar-pelajar yang memakai hijab yang membabitkan layanan berbeza di imigresen contohnya. Namun para pelajar merasakan bahawa dengan pemakaian hijab ini, mereka perlu bersedia untuk menjawab persoalan masyarakat luar tentang agama mereka dan sebab-sebab pemakaian. Keupayaan menjalankan ibadah agama masing-masing dan berpeluang untuk menjalani gaya hidup berlandaskan agama masing-masing boleh dikategorikan sebagai fasa pemulihan pelajar dalam proses awal penyatuan perbezaan cara hidup.

Berkaitan sistem sokongan pula, kehadiran sistem sokongan yang kukuh dalam kalangan rakan-rakan senegara merupakan faktor yang penting. Ini selaras dengan pandangan Rohaiza et al. (2017) yang membicarakan tentang kepentingan keserakanan dalam kalangan pelajar senegara. lanya mewujudkan satu sense of belonging dalam kalangan pelajar tersebut. Mereka mempunyai tempat untuk berkongsi cerita berkaitan Malaysia dan mempunyai rakan-rakan yang dapat memahami apa yang mereka lalui di United Kingdom. Persamaan dari segi negara mengukuhkan semangat kerakanan dalam kalangan pelajar Malaysia. Jikalau literatur lepas seperti Rabia (2017) dan Abdul Latiff et al. (2014) banyak mencadangkan program anjuran universiti untuk mengukuhkan perhubungan dan integrasi 
pelajar tempatan dan antarabangsa, kumpulan pelajar yang dikaji ini tidak memberikan penumpuan kepada aspek tersebut. Mereka lebih menekankan kepada kepentingan seseorang individu untuk mempunyai kekuatan mental dan fizikal sebagai seorang penghijrah di luar negara.

Seyedali et al. (2019) telah membincangkan tentang stress diperingkat akulturasi dan salah satu kesukaran itu adalah untuk berkomunikasi dan menjalinkan hubungan dengan masyarakat tempatan. Pengalaman pelajar yang dikaji ini menyokong pandangan Seyedali et al. (2019) dan Abdul Latiff et al. (2016). Sememangnya agak sukar untuk pelajar Malaysia berinteraksi dan berkomunikasi dengan masyarakat tempatan, namun pelajar harus mencuba untuk lebih menikmati pengalaman antarabudaya di luar negara. Keupayaan untuk berintegrasi dengan masyarakat tempatan ini akan melengkapkan proses adaptasi berdasarkan Model Keluk-U.

\section{KESIMPULAN}

Kehidupan pelajar di luar negara sememangnya berbeza jikalau dibandingkan pada zaman dahulu. Kini, para pelajar Muslim Malaysia berpeluang untuk menjalani ibadah agama dan mempraktikkan gaya hidup berlandaskan Islam di United Kingdom. Sememangnya terdapat percanggahan dengan cara masyarakat tempatan menjalani aktiviti harian mereka namun migrasi telah memperkayakan United Kingdom dengan pelbagai budaya. Perbezaan budaya ini mula difahami dan dihormati dan ini memudahkan sekumpulan masyarakat dari budaya yang berbeza untuk mempraktikkan budaya mereka.

\section{PENGHARGAAN}

Artikel ini dibiayai oleh Geran Kecil Penyelidikan (GKP) FSSK SK-2019-018

\section{BIODATA}

Prof. Madya Dr Abdul Latiff Ahmad adalah Professor Madya di Pusat Kajian Media dan Komunikasi, Fakulti Sains Sosial dan Kemanusiaan, Universiti Kebangsaan Malaysia. Beliau juga memegang jawatan sebagai Pengarah Pusat Hubungan Antarabangsa, UKM. Bidang penyelidikan utama beliau adalah komunikasi antarabudaya, media sosial dan pengantarabangsaan. E-mel: alba@ukm.edu.my 


\section{RUJUKAN}

Abdul Latiff Ahmad, Nur Zalila Md Zamri, Ali Salman, Emma Mirza Wati Mohamed, \& Hasrul Hashim. (2014). Isu-isu dan masalah adaptasi antarabudaya dalam kalangan pelajar Malaysia di United Kingdom dan Australia. Jurnal Sains Sosial dan Kemanusiaan, 9(2), 162-171.

Abdul Latiff Ahmad, Salma Ali, Ali Salman, \& Sabariah Mohamed Salleh (2016). Adaptasi antarabudaya pelajar Nigeria di Malaysia. Jurnal Komunikasi: Malaysian Journal of Communication, 32(2), 105-120.

Ahrari, S., Krauss, S. E., Suandi, T., Abdullah, H., Sahimi, A. H. A., Olutokumbo, A. S., \& Dahalan, D. (2019). A stranger in a strange land: Experiences of adjustment among international postgraduate students in Malaysia. Issues in Educational Research, 29(3).

Baklashova, T. A., \& Kazakov, A. V. (2016). Challenges of international students' adjustment to a higher education institution. International Journal of Environmental \& Science Education, 11(8), 1821-1832.

Balqis Mustafa, \& Abdul Latiff Ahmad. (2019). Adaptasi antarabudaya penghijrahan pelajar Malaysia ke negara Asia. Jurnal Komunikasi: Malaysian Journal of Communication, 35(2), 18-34.

Chen, S.-H. (2009). A study of international students' life situation - A case study of the international students in University of Twente (Tesis Sarjana, University of Twente).

Costello, J. (2015). Students' stories of studying abroad: Reflections upon return. Journal of International Students, 5(1), 50-59.

Ding, X. (2016). Exploring the experiences of international students in China. Journal of Studies in international Education, 20(4), 319-338.

Kim, Y. Y. (2000). Becoming intercultural: An integrative theory of communication and crosscultural adaptation. Thousand Oaks, CA: Sage Publications.

Lysgaard, S. (1955). Adjustment in a foreign society: Norwegian Fulbright grantees visiting the United States. International Social Science Bulletin, 7(1), 45-51.

Macionis, J., \& Gerber, L. (2010). Sociology (7th ed.). Toronto, Canada: Pearson Education.

McDermott-Levy, R. (2010). Going alone: The lived experience of female Arab-Muslim nursing students living and studying in the United States. Nursing Outlook, 59(5), 266-277.

Mulyana, D., \& Sri Eko, B. (2017). Indonesian students' cross-cultural adaptation in Busan, Korea. Jurnal ASPIKOM, 3(2), 144-156.

Nurul Syahidah Ahmad, \& Abdul Latiff Ahmad. (2018). Adaptasi budaya pelajar perempuan Islam antarabangsa di Universiti Kebangsaan Malaysia. Jurnal Wacana Sarjana, 2(4), 1-9.

Presbitero, A. (2016). Culture shock and reverse culture shock: The moderating role of cultural intelligencein international students' adaptation. International Journal of Intercultural Relations, 53, 28-38.

Rabia, H. M. A. (2016). Undergraduate Arab international students' adjustment to US universities. International Journal of Higher Education, 6(1), 131.

Rohaiza Rokis, Norhidayah Mat Zain, \& Nur Fatihah Md. Yusuf. (2017). A preliminary understanding on intercultural adaptation among African students in Malaysia: A groundwork study. Journal of Advanced Research in Social and Behavioural Sciences, 9(2), 9-19.

Wang, Y., Li, T., Noltemeyer, A., Wang, A., \& Shaw, K. (2018). Cross-cultural adaptation of international college students in the United States. Journal of International Students, 8(2), 821-842. https://doi.org/10.32674/jis.v8i2.116 